\title{
La Tomodensitometría Osea, un Método Indirecto de Valoración de las Distintas Cargas que actúan sobre el Esqueleto, por medio de la Medición de la Masa Osea
}

DRES. JUAN J. ZWART MILEGO Y MIGUEL A PRADAS CANO

\section{INTRODUCCION}

La Tomodensitometría Osea ofrece un método de tipo indirecto para valorar las cargas que actuan sobre el esqueleto, a través de las alteraciones de la masa ósea que aparecen en los huesos debido a alteraciones en sus propiedades biomecánicas. Los modernos osteodensímetros hacen posible medir con gran precisión las zonas del hueso de interés y sobre cualquier localización, siendo rápido de efectuar y sin molestias para la persona explorada. Tiene mucho interés en el estudio articular, aportando unos datos sobre el contenido mineral óseo que hasta ahora no se habían considerado cuantitativamente.

\section{TÉCNICA}

Para realizar las pruebas se ha empleado un Tomodensímetro Oseo de absorciometría por doble energía de rayos $\mathrm{X}$, en su variante de cuantificación digital (QDR).

\section{BASE PATOGÉNICA}

El tejido óseo tiene una gran actividad celular, se encuentra en continua remodelación durante la vida del individuo, alternandose o de forma simultánea las fases de aposición y las de reabsorción ósea, como resultado de diversas circunstancias, siendo principalmente las debidas a alteraciones de tipo físico. Varias son las leyes enunciadas al respecto, la «Ley de las transformaciones de Wolf» dice: «la arquitectura del hueso depende de su función de sostén. Si la función cambia, la arquitectura varía adaptándose a la nueva circunstancia». Como aplicación amplia de la ley anterior y de la « $3^{\mathrm{a}}$ ley de Roux», puede decirse que en general las partes sometidas a mayores cargas incrementan la cantidad de tejido óseo, aumentando su densidad media y parcialmente esclerosándose; mientras que de forma contraria las partes con menores cargas resultan con una osteopenia.

\section{INTERPRETACION DE LOS DATOS}

Los valores que se pueden obtener por densitometría ósea hacen referencia a la cantidad del contenido mineral, ya sea de forma total o en zonas localizadas; y a su distribución, de forma regular o irregular. En los huesos cortos, zonas epifisarias o a nivel vertebral, puede diferenciarse la parte cortical y la parte esponjosa.

Con los valores mínimos obtenidos en ciertas zonas pueden deducirse circunstancias de predisposición o peligro de fractura, como sucede con el triángulo de Ward en el cuello femoral. La imágen digitalizada en color proporciona un auténtico mapa densitométrico de la zona a estudiar, con variaciones en el color o en la tonalidad. Esquematizando:

$\begin{array}{ll}\text { Alteraciones del tejido óseo mensurables por QDR } \\ \text {-Cantidad } & - \text { Total. } \\ & \text { - Localizada. } \\ & \text { - Regular. } \\ \text {-Distribución } & - \text { Irregular. } \\ & - \text { Cortical. } \\ \text {-Diferenciación } & - \text { Esponjosa. } \\ & - \text { Zona esclerosada. } \\ & - \text { Mapas colorimétricos. } \\ \text {-Función } & \text { - Valores mínimos. }\end{array}$

\section{MÉTODO}

En las mediciones desitométricas es necesario seguir un protocolo muy estricto para conseguir una uniformidad en los resultados. En primer lugar hay que colocar al paciente en una posición ya establecida que sea fácil- 
mente reproducible. En las extremidades inferiores existe la gran ventaja de poder hacer los estudios de regiones homólogas, de forma simultánea, comparativa y simétrica; evitando así que existan diferencias en los estudios comparados. En segundo lugar, posteriormente al analizar las imágenes hay que realizar siempre mediciones que puedan ser equiparables; al efecto se han dispuesto de unos campos o ventanas medidos milimétricamente a partir de unos puntos conocidos. Los valores obtenidos se almacenan en la memoria del ordenador para crear una futura Base de Datos que pueda ser de interés consultar.

En las extremidades inferiores se han estandarizado 7 regiones que pueden ser medidas de la forma simultánea ya expuesta y que tiene un interés por su frecuente patología:

1.- Ambos anillos isquiopubianos. F.

2.- Ambas cabezas y cuellos femorales. F.

3.- Ambas rodillas. F. Totales y mesetas tibiales.

(Fig. 1)

4.- Ambos tobillos. F

5.- Ambos retropies. P. Calcáneos, subastragaliasa y cuboides. (Fig. 2).

6.- Ambos antepies. DP. $1^{\circ}$ radio. (Fig. 3 ).

7.- Ambas extremidades inferiores completas. F. (Fig. 4)

Estas regiones son de fácil acceso, poseen puntos anatómicos de referencia externa que ayuda en la colocación, y son regiones que dan imágenes claras y bien definidas. No obstante pueden realizarse análisis densitométricos en cualquier lugar que se necesite, pues no existen limitaciones en el empleo de esta técnica. Aparte es conveniente realizar siempre una valoración también de la columna lumbar, para conocer el estado de la calcificación en el esqueleto axial. La columna vertebral es punto de inicio con gran frecuencia d elos estados osteoporóticos por su gran contenido en tejido óseo esponjoso que se afecta precozmente.

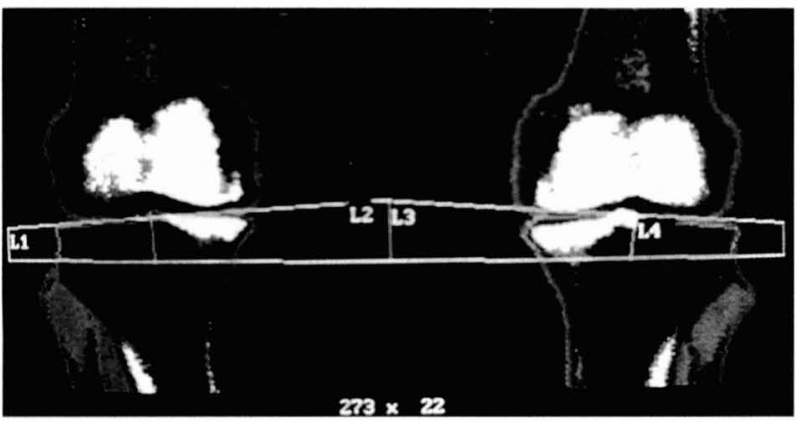

Figura 1: Estudio de las mesetas tibiales de forma comparativa ! simétrica. Paciente con genu varo, se observa una fuerte esclerosis de la meseta interna bilateralmente. Por medio de filtros es posible intensificar ciertos colores, con la intención de hacer más patente algunas características biomecánicas. En las imágenes es posible estudiar la distribución de cargas que se desplazan por todo el pilar interno tibial.

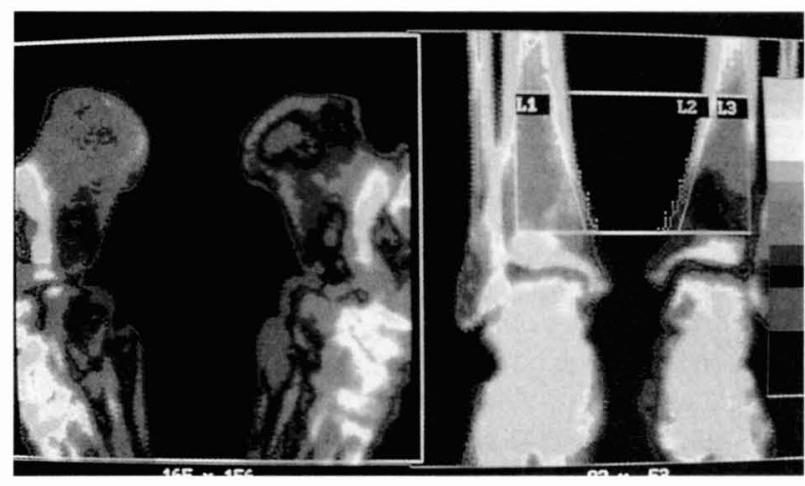

Figura 2: Se trata de un paciente con fractura del hueso cuboides del pie izquierdo, de tres meses de evolución. Colorimetricamente se observa una osteoporosis marcada en calcáneo y epifisis tibial distal de la tibia, lado izquierdo, de origen distrofico reflejo. Aunque no aparezca junto a las imágenes, la cantidad de calcio puede ser cuantificada.

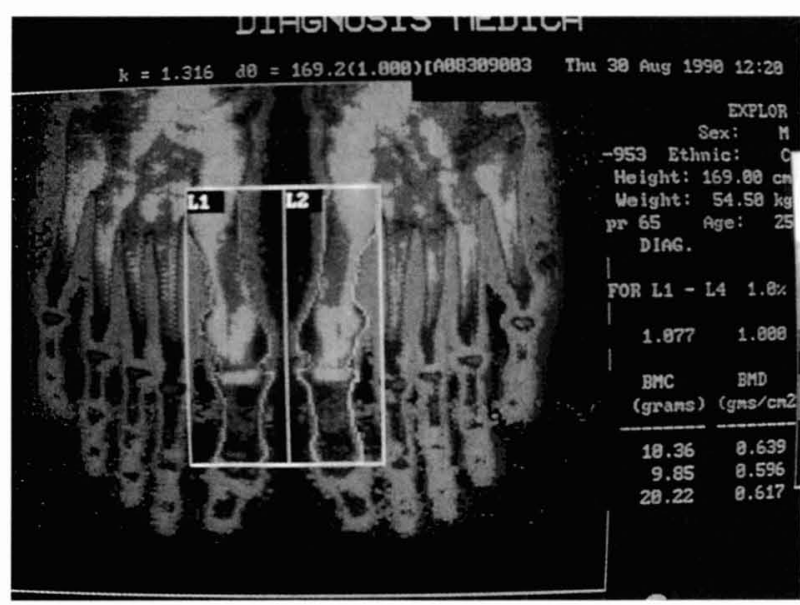

Figura 3: Ambos antepies de una persona normal. siguiendo e protocolo de medición, se valoran el $1^{\circ}$ metatarsiano y la $1^{a}$ falange, en este caso con una masa ósea dentro de la normalidad. Cuando existe una alteración del apoyo del primer radio, estas cifras pueden disminuir notablemente.

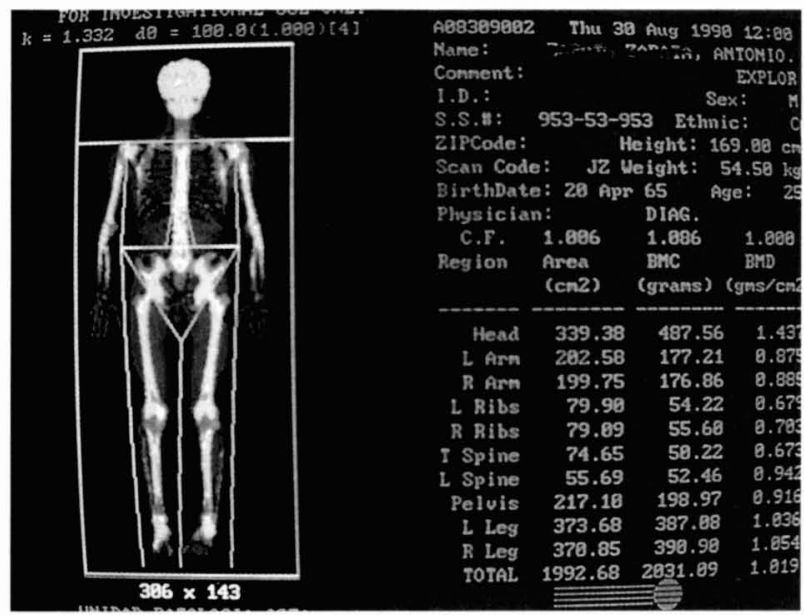

Figura 4 : Cuerpo entero. Se analizan 10 regiones. La figura mues tra normalidad en el esqueleto apendicular y cifras bajas en el axial. En ocasiones puede observarse una diferencia significativa entre las extremidades inferiores, especialmente en los casos de distrofias reflejas de cualquier etiología. 
Cuando existe material de osteosíntesis, prótesis y cemento óseo, hay que usar una técnica especial de exclusión de dicho material que solamente valore la parte ósea.

\section{RESULTADOS}

Son diversas las circunstancias que pueden causar disminución de la masa ósea de forma unilateral, tales como la inmovilidad, disminución de la actividad muscular, dolor, esguinces, fracturas, intervenciones o los trastornos axiales articulares; produciendose de forma total o localizada, con distribución regular o irregular, pero siempre debido a un mecanismo de tipo distrófico reflejo. Los datos aportados tienen el doble valor de conocer el estado actual y de la posibilidad de un seguimiento evolutivo, para conocer el curso de un proceso o la actividad de un tratamiento.

Los incrementos de contenido mineral no acostumbran a afectar a la totalidad de la región estudiada, sino a zonas localizadas por la producción de un área esclerosada o condensante. Es muy significativo causado por degeneraciones artrósicas y en los procesos osteonecróticos (aparece un área hipodensa rodeada de otra esclerosada, aunque muchas veces sólo se observa esta última). También elevan mucho los resultados las zonas de artrodesis, callo posfractuario, condrocalcinosis, o aquellos procesos con calcificaciones o aplastamientos óseos. Cuando existe una condromatosis sinovial o la presencia de una exóstosis, a veces el resultado es aleatorio pues pueden corresponder a áreas de baja densidad cálcica.

\section{CONCLUSION}

Con la Densitometría Osea se dispone de una prueba no cruenta, fiable, precisa y reproducible, aplicable a cualquier localización. Que puede ser de gran ayuda aportando conocimientos sobre el estado de la calcificación ósea. Estando relacionada la estructura del tejido óseo, desde los elementos celulares y sistemas haversianos, hasta la trabécula y la morfología final del hueso entero, a las necesidades físicas, especialmente su resistencia a la compresión o sea a la deformidad frente a las solicitudes biomecánicas. Resulta de gran interés un método de las características descritas, que puede hacer cuantificable el contenido mineral óseo.

\section{BIBLIOGRAFIA}

1. Avioli, L.V. Increasing osteoporosis screening referrals. Applied Radiology. 1988; 17, 4. 25-34.

2. Calcio: Aspectos clínicos y experimentales. Rev. Triángulo Número monográfico. Ed. Sandoz. 1986; 24. 3 y 4.

3. Civitelli, R., Gonelli, S. et al. Bone turnover in Postmepausal Osteoporosis. J. Clin. Invest. 1988; 82. 1268-1274.
4. Cooper, C., Barker, D.J.P., Wickham, C. Phisical activity muscle strecht, and calcium intake in fracture of the proximal femur in Britain. Br Med J. 1988; 297. 1443-1446.

5. Diaz, M., Rapado, A., Yagüe, M. Utilidad de la medición de la masa ósea en el esqueleto axial y periférico. Rev Esp Reumatol. 1991; 18, 5. 23.

6. Galan. F.. Moruno, R., et al. Cuantificación de la masa ósea en 1990. ¿Cómo?, ¿Dónde?, ¿Cuándo?. Inflamación. 1990; 93, 3 187-194.

7. Heaney, R.P., Barger-Luz, M.J. Calcio, metabolismo óseo y fallo estructural. Sandorama. 1987; 11-18.

8. Gobelet, C. Algoneurodistrofia. Sandorama. 1984; 5-11.

9. Jelly, T.L., Slovik, D.M., et al. Quantitative Digital Radiography «versus» Dual Photon Absorcieometry of the lumbar Spine. J Clin Pharmacol Ther. 1988; 13. 125-130.

10. Llano, L.F., Parreño, J.R., Robles, E., et al. Fracturas de calcáneo. Síndrome de Sudeck. Tratamiento. Ed. Sandoz. Barcelona. 1988.

11. Miravet, L., Marie, P., Vernejoul, M.C. Control celular de remodelamiento óseo. Dolor \& Inflamación. 1001; 4, 4. 215-219

12. Morales, A., Perez, F., Corres, J. Implicaciones del carácter cuántico del remodelado óseo, en el concepto y evaluación de la osteoporosis. Dolor \& Inflamación. 1990; 3, 8. 404-408

13. Nordin, B.E.C., Barnett, E. Lumbar Spine Densitometry. Br Med J. June. 1962; 1793-1796.

14. Pirnay, F., Bodeux, M., Crielard, J.M., et al. Bone Mineral Content and Physical Activity. Int J Sports Med. $1987 ; 8.331-335$

15. Rico Lenza, H. El síndrome osteoporótico. Ed. Sandoz. Barcelona. 1985.

16. Roger, L. La distrofia simpaticorefleja en traumatología. Ed. Sandoz. Barcelona. 1986.

17. Sartoris, D.J. Radiographic technique may renew credibility of bone densitometry. Diag Imaging. April. 1988; 146.

18. Sartoris, D.J., Resnick, D. Digital radiography may spark renewal of bone densitometry. Diag Imaging. January. 1988; 145-151.

19. Stevenson, J.C., Lees, B., et al. Determinants of bone density in normal woman: risk factors for future osteoporosis. Br Med J. 1989; 298. 924-928.

20. Stevenson, J.C., Whitehead, M.I., et al. Dietary intake of calcium and posmenopausal bone loss. Br Med J. 1988; 297. $15-17$.

21. Zielger, G., Fournier, M., Euller, L. Sport et masse osseuse. L.M.M. médecine du sud-est. 1989; 25. 1264912654 .

22. Zwart, J.J., Pradas, M.A. Estudio densitométrico de las cargas que actuan sobre la rodilla. XIII Symposium de la Sociedad Ibérica de Biomecánica. Madrid, 20 octubre 1990.

23. Zwart, J.J., Pradas, J.C., Parunella, C. La tomodensitometría ósea aplicada a la extremidad inferior. Arch Diag med. 1990; 6. 14-16.

24. Zylstra, S., Hopkins, A., Erk, M., et al. Effect of Physical Activity on Lumbar spine and Femoral Newck Bone Densities. Int J Sports Med. 1989; 10. 181-186. 